\title{
RAMÓN ZORRILLA
}

\section{¿Qué pasa en México?}

$\mathbf{L}$

a pregunta es de una extrema amplitud. Puede contestarse con casi infinitas respuestas, desde "hemos tenido un mediano temblor de tierra hace diez días" o "en este julio ha llovido como no ocurría desde hace veinte años", hasta "los mexicanos estamos un tanto cuanto deprimidos", "el costo de la vida sigue subiendo" o "renunció el gobernador de Guanajuato".

El centrarnos más en el campo de lo social y lo político no reducirían hasta hacerlas manejables las posibilidades de los censos y de respuesta: se puede hablar en esos terrenos que - posiblemente - 76 millones de habitantes este día nacen, mueren, engendran, consımen, trabajan - o no - ven televisión, van al cine, asisten a mitines de apoyo, leen periódicos y se quejan.

Puede ceñirse aún más la extensión de la pregunta y formularla en estos términos: ¿Qué pasa en México que antes no pasaba?

Pero el adverbio antes podría remitimos a otros milenios - hasta el Hombre del pedregal - o varios siglos; al tiempo de Izcóatl o al virreinato o a los tiempos de Don Porfirio...

Creemos que la pregunta es manejable si reducimos la inmensidad de ese antes a ese ciclo cosmogónico que es entre nosotros un sexenio.

Nos permitimos entonces reformular la pregunta ¿qué pasa en México? de la siguiente manera: ¿Qué ocurre en México que no ocurría hace seis años? En esta pregunta van necesariamente implicadas muchas otras: ¿qué de lo de aquello permanece? ¿qué es diferente? ¿qué es lo que es ya otra cosa muy distinta?.

Hace seis años la pregunta ¿qué está pasando en México? no era de ningún modo apremiante. El Presidente - como ahora - estaba a poca distancia de su segundo informe. A menos de dos años de la devaluación de 1976 el común de la gente se había resignado a un dete- 
rioro económico y había más bien optimismo en cuanto a una recuperación. La culpa de los males económicos se atribuía - nunca explícitamente en el sexenio oficial- unánimemente al gobierno del Presidente anterior.

En lo internacional el Presidente Carter entraba a su segundo año de gobierno. Somoza enfrentaba una revolución en Nicaragua, el Sha gobernaba Irán. Moro era asesinado en Italia. En Libano había crisis y se combatía en Beirut. En Campo David se firmaba acuerdo entre Sadat de Egipto y Beguin de Israel... El Papa era Pablo VI (falleció en agosto de ese año).

En lo político los acontecimientos mayores en México habían sido las renuncias requeridas de los Secretarios de Hacienda y Programación y Presupuesto.

En la Dirección de Información de Presidencia se había cambiado de tres titulares.

En política electoral el PAN era prácticamente el único partido de oposición. Nacía el periódico Uno más uno.

Se denostaba a la corrupción.

El PRI (antes PRN, antes PRM) entraba en su año quincuagésimo. El sistema político mexicano se presentaba casi invulnerable.

En la política internacional mexicana no había grandes novedades.

¿Qué pasa ahora?

Con la llamada Reforma Política, con la aparición inmediata después de un partido político de izquierda, el PSUM, el sistema político funcionó como antes había funcionado durante medio siglo con el PAN.

Por muchos conceptos el poder del Ejecutivo se ha amplificado. El nuevo Presidente recibió potencialmente mucho más que lo que los Presidentes tuvieron seis, doce, dieciocho, veinticuatro o treinta años antes. La nacionalización de la banca puso en manos del poder estatal, más que el dinero, "el poder del dinero" que antes se repartía en diversos grupos de iniciativa privada que manejaban las finanzas del país.

Las reformas constitucionales de diciembre de 1982 reformaron por otra parte las facuitades - esto es, el poder - del Ejecutivo en materia económica. 
Sin embargo en un sector de la opinión pública se afirma que el actual Gobierno ha dado un giro: ia la derecha!

En apariencia los sectores empresariales parecen más agresivos que en cualquier otro tiempo. La izquierda, por su parte, parece más desunida que nunca antes.

Las relaciones Gobierno-sector obrero no han sido tranquilas. Si las discrepancias no han llegado a mayores esto parece ser más bien acreditable a la experiencia política de los líderes obreros que a la habilidad política de los funcionarios oficiales.

Dentro del equipo básico del Gobierno Federal no se han dado cambios importantes.

En lo que se refiere a las entidades federativas se sintió brusquedad en el retiro de dos Gobernadores, el de Yucatán y -más recientemente- el de Guanajuato. En el segundo caso parecieron acentuarse divergencias entre lo que podría llamarse parte polítca y parte técnica del actual Gobierno.

Por primera vez en la historia de México se han dado tres gobiernos consecutivos en los que el Primer Mandatario no tuvo antes ningún cargo de elección popular.

La experiencia política de los miembros del gabinete es mucho menor a la de sexenios anteriores. En el propio Poder Legislativo muchos diputados y senadores (incluso el líder de estos últimos) han llegado al cargo desde posiciones anteriores no electorales.

El sector político y el sector técnico parecen tener lenguajes distintos y formas diferentes de pensar.

En otro orden, en el manejo de política de comunicación y de información y propaganda parece darse una contradicción entre la que se maneja desde la Presidencia y la política seguida por otras Secretarías, particularmente la de Gobernación.

Si en el segundo año de López Portillo se podía sentir en la opinión pública resignación y cierto optimismo, creemos que en este momento no es notable ni la una ni el otro en la opinión pública. Los medios de comunicación son en cierto modo más críticos que hace seis años y mucho menos autocensurados.

En relación con la administración anterior, las discrepancias que siempre han existido (algunos sociólogos hablan de una necesaria "revolución sexenal" -incruenta que en México balancea y equilibra el sistema-) son ahora mucho más notables y en alguna forma transfieren mucho más que antes a la opinión pública. Casos como Díaz 
Scrrano o Durazo ciertamente pueden denigrar al anterior sexenio, pero afectan también a la credibilidad de todo el conjunto que desde afuera se entiende por "gobierno" o por "sistema" más allá de cualquier período presidencial.

En lo internacional México ha tomado posiciones y actitudes que de ningún modo rompen en teoría con su tradición. Pero ahora revelan una actividad y no una pasividad en ese terreno.

El contexto internacional es muy distinto que el de hace seis años. Entre el Presidente Carter y el Presidente Reagan es evidente una gran diferencia. En Beirut parecen apenas cesar los combates, el Sha está bajo tierra y el Gobierno que le sucedió llama Satán a los EE.UU. Centroamérica arde.

\section{¿Qué pasa pues en México?}

1. En lo económico la crisis para el común de la población es más fuerte que hace seis años. El salario real disminuye notablemente. Junto con esa crisis económica - a diferencia de lo que pudo haber ocurrido en sexenios anteriores - hay en muchos sectores cansancio y desesperanza respecto de una justa mejoría en las condiciones de vida.

2. La credibilidad en cuanto a acciones gubernamentales que le puedan llevar a esa mejoría es muy baja o nula. Se señalan innumerables contradicciones entre los planes de desarrollo y la realidad cotidiana. Alzas en el costo de la vida, etc.

3. La Comunicación entre Gobierno y población no parece estar lo suficientemente instrumentada y posiblemente puede estar más bien absolutamente sesgada como revelan los medios de difusión.

4. En el orden de las relaciones internacionales México es afectado en muchas formas - económica, social y políticamente - por un desorden creciente e ingobernable (entropía, diría un comunicólogo).

5. Las presiones que en lo internacional pueden recibirse ahora son mucho más intensas que en otro tiempo. 